\title{
nature
}

\section{Refocusing NASA's vision}

\section{Ballooning costs for NASA's next space telescope are putting other worthwhile projects at risk - and carry lessons for future mission planning.}

\begin{abstract}
t is now clear that when NASA first requested funds for a Next Generation Space Telescope a decade ago, the project's advertised price of under $\$ 1$ billion was little more than a fiction. But it was a fiction that the space agency, the Congress and many in the astronomy community wanted to believe.
\end{abstract}

The consequences of this self-deception are now coming home to roost (see page 140). The James Webb Space Telescope (JWST), as the project is now known, is by far the largest item in NASA's science programme. Its serious cost overruns, together with the space agency's transfer of money from the science budget to support future astronaut missions, are causing the indefinite postponement of other exciting projects. And while smaller missions can be cancelled if they break their budgets - Dawn, NASA's mission to the asteroid

"If the telescope'scurrent price had been on the sticker when it wasfirst offered for sale, the project might never have got off the drawing board." belt, suffered just this fate only last week - a flagship mission such as the JWST is all but immune to such a drastic disciplinary measure.

This chain of events has cast an unfortunate light on a means of project selection that has often been exalted as a model for consensus building between competing research projects: the Decadal Survey for astronomy, conducted by the US National Academy of Sciences. Back in 2000, the Decadal Survey backed seven major projects and a dozen or so smaller ones, and suggested that $\$ 4.6$ billion would pay for the lot of them. The $\$ 1$-billion project that was to become the JWST was top of the list. NASA's best estimate for the cost of this instrument alone is now $\$ 4.5$ billion.

A cynic might suppose that the telescope's budgetary trajectory has been cleverly crafted; in the beginning it looked small enough to be affordable, and once under way it quickly became too big to be cancelled. If the telescope's current price had been on the sticker when it was first offered for sale, the project might never have got off the drawing board.

\section{All inclusive}

The same could be said, in fact, of the much-admired Hubble Space Telescope, which the JWST will in some regards replace. It is by no means certain that Congress would have given the go-ahead for Hubble had it known that its final lifetime cost, including servicing missions on the space shuttle, would reach about $\$ 12$ billion at today's prices.

That figure for Hubble, although suitably astronomical, does at least have the benefit of being fully inclusive: it contains overheads, operations, inflation and everything else. One of the reasons that the JWST now looks so expensive is that it is the first large NASA project to be scrutinized under the agency's new policy of declaring costs in this way.
Painful as such declarations may be, they will ultimately serve the agency better than the prevarications of the past. But good accounting will not in itself ensure that funding for major projects flows in the orderly manner that is needed if they are to stay on the right budgetary track. At the moment, it is impossible to predict whether NASA's science budget will remain stable or be cut further as the costs of a new human exploration programme and the legacy of current obligations add up. The previously envisaged growth in the budget certainly seems unlikely to materialize.

In such circumstances, flagship missions as ambitious as the JWST - missions to study planets round other stars, or return samples from the surface of Mars, for example - will be few and far between, if any fly at all. International cooperation will doubtless be explored as a way forward, and this should involve genuine collaboration at the planning stage and cost-sharing from the outset, rather than the secondary roles that Europe and Canada play in the JWST. But such collaborations require real political commitment at the very highest level and, as the International Space Station amply demonstrates, they suffer from many drawbacks of their own.

\section{A question of balance}

Even if costs are shared internationally, there is a limit to how much funding space-based astronomy can expect to receive compared with other scientific disciplines. Astronomers may say it is not their fault that their tools are more expensive than those of other scientists; beryllium mirrors unfolding in deep space inevitably cost a great deal more than butterfly nets. But while it is right that every dimension of human curiosity should have some call on the public purse, it is not reasonable to expect the guardians of that purse to choose between the costly and the cheap with complete equanimity. Even with the
"The astronomy community must therefore learn to live within its means, starting with its next Decadal Survey." current cuts, NASA's science receives more than $\$ 5$ billion a year, and few outside space science regard that as insufficient.

The astronomy community must therefore learn to live within its means, starting with its next Decadal Survey. Princeton physicist Joseph Taylor, who co-chaired the last one, told Congress last week that the once carefully crafted plan is becoming unbalanced: "The current NASA budget," he said, "is tilted to an unhealthy extent toward the large missions." Given the choice, most in the community would probably prefer any funds freed up by the ending of old projects to go on small, focused missions and research grants, rather than on the development of future super-missions. As a result, the next survey will need to consider a more balanced portfolio of less heroic ambition. And it will have to look at it with an accountant's squint, as well as an astronomer's far-seeing gaze. 